\title{
The use of high-definition video technology on diabetes management
}

\author{
Amal Abdel-hameed Elabbassy * \\ Community Health Nursing Department, Faculty of Nursing, Menoufia University, Al Minufya, Egypt
}

Received: March 8, 2015

Accepted: April 21, $2015 \quad$ Online Published: May 10, 2015

DOI: $10.5430 /$ jnep.v5n7p109

URL: http://dx.doi.org/10.5430/jnep.v5n7p109

\begin{abstract}
Background: Diabetes, a metabolic disorder, has reached epidemic proportions in developed and developing countries. So, the Use of High-Definition Video Technology has gained acceptance as a tool for improving diabetes management. The aim of this study was to determine the effect of using High-definition video technology on diabetes management.

Methods: Subjects: All 120 diabetic children, in the Diabetic center in the EL Mogamaa EL Teby AL Shamal, Menoufia Governorate, Egypt. Instruments: It consisted of four tools: 1) Questionnaire for socio demographic data; 2) Questionnaire for nutritional practices and practicing of exercise; 3) Observational checklists, guidelines for testing urine reagent strips for acetone or sugar, guidelines for Diabetic foot and nails care and guidelines Steps in Performing a capillary blood glucose test by using the home device; 4) Diabetic child's investigations' results (fasting blood glucose level, postprandial blood glucose level and glycosylated hemoglobin level) were collected from child's record. All tools were used for pre-post intervention.

Results: The study showed a statistical significant reduction in fasting blood sugar, Post prandial blood sugar and glycosylated hemoglobin level of cases group after intervention $(120.57+29.13,165.57+29.13$ and $7.08+1.56$, respectively) compared with cases group before intervention $(166.37+27.66,232.80+57.02$ and $9.61+1.94$, respectively). Also, there was statistical significant improvement in care of feet and nails, blood glucose monitoring and nutritional practices of cases group after intervention $(64.25+2.81,36.35+2.44$, and $10.88+1.45$, respectively) compared with control group $(23.21+1.37,17.63+$ 2.11 , and $5.28+1.37$, respectively).

Conclusions: The implementation teaching-assisted High-Definition Video Technology has succeeded in achieving significant improvement in diabetic children' diabetes management practices skills. Recommendations: implementation of teaching-assisted High-definition video technology for all patients' health education fields.
\end{abstract}

Key Words: Diabetes health education, Diabetic children, High-definition video technology

\section{INTRODUCTION}

During the last twenty years the prevalence of diabetes has increased dramatically in many parts of the world and the disease is now a worldwide public health problem. ${ }^{[1]}$ So, the burden of diabetes is increasing worldwide. It has been calculated that, in 2030, the total number of subjects with diabetes mellitus will be 366 million. The increasing prevalence of the disease combined with the fact that the disease is associated with increased morbidity and mortality emphasize the importance of effective diabetes care. ${ }^{[2]}$ Chronic illnesses account for $70 \%$ of all deaths. Diabetes increases the risk of heart disease, stroke, kidney failure, and blindness, among other morbidity. However, the risk of acquiring a chronic disease, such as diabetes, and subsequent morbidity and/or disability, can be decreased by modifying health behaviors. ${ }^{[3]}$

The future of diabetes care lies in finding ways to help pa-

\footnotetext{
*Correspondence: Amal Abdel-hameed Elabbassy; Email: moley_elabassy@yahoo.com; Address: Community Health Nursing Department, Faculty of Nursing, Menoufia University, Minufya, Egypt.
} 
tients and providers deal successfully with the complexities of the disease by improving the system of care, expanding the reach of interventions, and empowering patients to engage in self-care behaviors. ${ }^{[4]}$ Also, Self care is the cornerstone for all individuals with diabetes and the essential component to the successful achievement of health-related out-comes. ${ }^{[5]}$ Healthy People 2010 recommend that high-quality information and support services be developed for specific health problems and health-related decisions that are culturally sensitive and appropriate for various educational levels. ${ }^{[6]}$

Annually some 76.000 children aged less than 15 years developed type 1 diabetes worldwide. ${ }^{[7]}$ Approximately 1 in every 800 children and adolescent in the U.S. are affected with type 1 diabetes. ${ }^{[8]}$ In Egypt, Diabetes is an emerging public health problem. It affects nearly 3.9 million individuals with an expected increase by 2025 to nearly 9 million. ${ }^{[9]}$ The frequency was higher among females than males and equal in urban and rural areas. ${ }^{[10]}$ A growing body of literature suggests that information technology (IT), such as computer, Internet and cell phone technology, holds great promise in enhancing diabetic care. ${ }^{[11-14]}$

\subsection{Literature review}

Information and communications technologies are resources to provide the information to the public in order to generate behavioral changes. Physicians' offices are a logical setting for providing this information. However, the delivery of quality, specialty healthcare services to rural populations can be a difficult and challenging process. Many residents live in areas that do not have access to health care or health and wellness education services. Also, rural health clinics lack the financial resources to provide commercially available patient education materials. These clinics rely on pamphlets from pharmaceutical companies to give their patients health information. The information contained in these handouts may be commercially biased or become outdated by the time the last pamphlet is distributed. ${ }^{[15]}$

Technology now plays an increasingly important role in diabetes healthcare and is continuing to revolutionize day-today management (and treatment of complications) for millions of people with the condition, improving the prognosis and reducing healthcare costs. ${ }^{[16]}$ Moreover, technology has helped diabetes management to become easier and patients have now a more exact diagnosis, care plan and follow up care. The number of people suffering from diabetes is getting more and more worldwide. The task of preserving desired glucose level is challenging for both patients and their families. ${ }^{[17]}$ Successful diabetes control relays on strict patient adherence to regimen of blood glucose monitoring, use of medication, 110 skin care, diet besides exercise. If diabetes is not treated correctly it will cause more serious problems in other body functions e.g., kidneys, nerves, feet, and eyes. ${ }^{[18]}$

Personal Glucose Monitors were a Technological Breakthrough in having Personal Control over Glucose Levels. There is no doubt that the advancement of the computer technology in the latter part of the previous century played a significant role in this field. The first personal monitors started to become available in the early 1980s. They have become smaller, faster with large data storage capacities for less amount of money. A personal BGL monitor provides a diabetic person with control over effectively managing the condition. For instance, it would be possible to make necessary adjustment in diet, exercise or medication based on the feedback. This ability to have accurate feedback on a regular basis has both short and long term positive effects in proper management of diabetes. The technology is progressing at a very rapid pace and changing and shaping the tools and equipment we use. It is interesting to note that there are already a few novel ideas which are gradually turning into practical and commercial products. ${ }^{[19]}$ For instance, needle free lancets using laser are becoming available. These devices will take the finger pricking discomfort out of the BGL testing process. GlucoWatch is another revolution which does not require any finger pricking. The glucose monitor is worn like a wrist watch and tests the BGL by drawing small amounts fluids from the skin. Hence, testing and data collection can be carried out on a regular basis.

The study measured the extent to which the foot-care teaching video was effective in altering the perception of the importance of foot care in persons newly diagnosed with diabetes mellitus type 2 who were referred to the Lawson Diabetes Education Centre in London, Ontario. The study's findings demonstrates a large increase in perceived knowledge of foot care after viewing the video, with a small drop in the onemonth follow-up. This compares favourably with the results of the actual foot-care knowledge question on the best way to examine one's feet. ${ }^{[20]}$ Also, there was a substantial improvement in scores at the post-video testing point compared with pre-video testing. In addition, the results indicated that a large proportion of the participants retained a significant amount of information immediately and one month after viewing the video. A high percentage of the patients enrolled in the survey reported an incorporation of best practice foot care into their daily lives.

\subsection{Aim of the study}

The aim of this study was to determine the effect of using High-definition video technology on diabetes management. 


\subsection{Research hypotheses}

(1) Diabetic children, who receive intervention using High-definition video technology, improve the skills and competences listed in diabetes management.

(2) Diabetic children, who receive intervention using High-definition video technology, will have better investigations' results than diabetic children who did not receive intervention.

(3) Diabetic children will have better investigations' results after intervention using High-definition video technology than before implementation of intervention.

\section{Methods}

\subsection{Design}

It is experimental pre/post-test design was used.

\subsection{Setting}

The study took place at central diabetes during 1 September 2012 to 25 February 2013. All the names of diabetic children who were between 12-14 years, and were registered in the computerized program for diabetic children were selected, they were 150 children. All the names were put in a bowl; the 120 names were selected randomly. The study sample was randomly assigned to one of two groups, 60 were control group and 60 were experimental group.

\subsection{Participants}

A simple random sample of 120 diabetic children who were enrolled in the computerized program for diabetic children registration. The children were selected according to the following criteria: A- Age of children was between 12-14 years was selected to understand the questionnaire and information which would be given, and had the ability for testing urine reagent strips for acetone or sugar, care for feet and nails and performing a capillary blood glucose test by using the home device. B- The children didn't attend any pediatric diabetic educational program before the study.

\subsection{Data collection instruments}

The data collection instrument was developed by the researcher after reviewing literature related to diabetes and using technology in diabetes management. And it was utilized in this study. It included three constructed tools.

Tool one: Interview questionnaire to collect socio demographic data including age, sex, educational level, mother's and father's education and occupation, disease duration etc.

Tool two: It consisted of questionnaire related to child's nutritional practices listed in dietary recommendations for children with diabetes are based on healthy eating recommendations suitable for all children and adults and be adapted to cultural, and family traditions and the psychosocial needs of the individual child as healthy source of carbohydrate, fiber and protein $e c t$. and scoring system ranged from (= not done and $1=$ done). ${ }^{[21]}$ Also, child's exercise practices listed in practicing exercise guidelines as testing blood glucose before and after exercise, assessment child's feet before and after exercise and eating starchy food before starting exercise ect. and scoring system ranged from $(0=$ not done and $1=$ done). ${ }^{[22]}$

Tool three: Observational checklists: it consisted of three observational checklists; Guidelines for testing urine reagent strips for acetone or sugar as getting a urine sample for detection the presence of acetone or sugar, exiting the bar and one out of the box for detection the presence of acetone or sugar...ect and scoring system ranged from $(1=$ not performed, 2 = performed, 3 = performed well, $4=$ performed excellent) ${ }^{[23]}$ Guidelines for Diabetic foot and nails care as examination of feet well every day looking for scratches, cuts, sores, redness, or any change in the skin, checking between toes, ect. and scoring system ranged from $(1=$ not performed, 2 = performed, 3 = performed well, $4=$ performed excellent ${ }^{[24]}$ and Guidelines Steps in Performing a capillary blood glucose test by using the home device as displaying the results of the last examination and match the numbers, Matching number on the screen of the device with the number on the box of examination tapes, ect. and scoring system ranged from $(1=$ not performed, $2=$ performed, $3=$ performed well, 4 = performed excellent). ${ }^{[25]}$

Tool four: Diabetic child's investigations' results (fasting blood glucose level, postprandial blood glucose level and Glycosylated hemoglobin level) were collected from child's medical record.

\subsection{Reliability of the tools}

Reliability was applied by the researcher for testing the internal consistency of the tool, by administration of the same tools to the same subjects under similar conditions on one or more occasions. Answers from repeated testing were compared (Test-re-test reliability $=0.7$ ).

\subsection{Validity of the tools}

They were tested for content validity by jury of four experts in the filed of Community Health Nursing and Pediatric Specialty to ascertain relevance and completeness.

Pilot Study was conducted to test the practicality and applicability of the questionnaire and to detect the problems that may encountered during data collection. Also to help to estimate the time needed to fill the questionnaire. The 
pilot study was conducted on 12 diabetic children. Children whom participated in the pilot study were excluded from the total sample. At the end of the study they were given copies from diabetes management videos on $\mathrm{CD}$.

\subsection{Ethical consideration}

An oral consent was obtained from children and their companies to participate in the study. During the initial interview, the purpose of the study and the procedures were explained and the oral consent was obtained from the participants. The subjects were assured that all information would be confidential to assure the confidentiality of the participants. Participants were assured that their participation in the study was voluntary and that they could withdraw from the study or can refuse to participate in the study. It was explained that there were no costs to participate in the study. Also, an oral approval was obtained from an ethic committee at faculty of nursing, Menofyia University, Egypt.

\subsection{Intervention's educational materials}

High-Definition Videos related items of diabetes management: High-Definition videos were adopted from different Internet sites. The content of videos included the following: - one video about a capillary blood glucose test by using the home device (5 minutes, 50 seconds) ${ }^{[26]}$ two videos about how to examine feet and ( 3 minutes, 49 seconds) $)^{[27]}$ and ( 8 minutes, 56 seconds $)^{[28]}$ and one video about testing urine reagent strips for acetone or sugar (3 minutes, 49 seconds). ${ }^{[27]}$

\subsection{Procedure and data collection}

An official approval was obtained from the dean of faculty of nursing and the director of the Diabetic center in EL Mogamaa EL Teby AL Shamal at Shebin El-kom that serves Menoufia Governorate.

According to the diabetic children's follow up visits' time schedule, the data were collected from the Diabetic Center in The EL Mogamaa EL Teby AL Shamal at Shebin El-kom. The researcher collected the data during the morning at two days/week from $10 \mathrm{AM}$ to $12 \mathrm{AM}$.

The questionnaire was filled while conducting interviews in the Diabetic Center for children. The purpose of the study was explained and their consent to participate was obtained. Filling the questionnaire related nutritional practices and practicing of exercise took about 15 minutes and three observational checklists took about 30 minutes (pre-test) for experimental and control groups. After that, monitoring blood glucose by blood glucose meter for teaching child how to use it. Diabetic child's investigations' results (fasting blood glucose level, postprandial blood glucose level and Glycosylated hemoglobin level) were collected from his medical report. It took two months.

Presentation of High-Definition videos related items of diabetes management: The researcher presented videos via computer's screen at the Diabetic Center, researcher's lab top or researcher's mobile and translated them. Also, the researcher demonstrated procedures and asked the subjects to re-demonstrated procedures. Moreover, the researcher gave copies of videos to children on their mobiles or CD and copies of written materials about different aspects of diabetes management as nutritional practices and practicing of exercise for diabetic patient with sufficient explanation of them.

\subsection{Implementation phase}

Intervention was implemented for 24 weeks in the mentioned setting. Participants (diabetic children) who were randomly assigned to the experimental group were interviewed by the researcher in groups (maximum, 5 children for each group according to their follow up's time). An appointment was made for them to return to Diabetic Center at a negotiated time and completed their questionnaires with the researcher. Based on each participant, the researcher identified topics for discussion. With this approach, the researcher was able to follow the participant's lead, gently guiding the interviews to focus on what the individual considered the most important aspect of diabetes self-management.

Participants were interviewed in a private room (diabetic center) in the morning time before diabetic children's follow up at diabetic center began.

First, participants watched videos about diabetes management via computer's screen at the Diabetic Center researcher's lab top or researcher's mobile. The researcher translated and explained videos. Also, the researcher demonstrated procedures and asked the subjects to re-demonstrated procedures. The researcher asked questions for brain storming and encouragement to actively participate and ask questions till the researcher was sure about their understanding of the subject. It took about 60-90 minutes.

Post-test was obtained for experimental and control groups. It took two months and it was finished at 25 February 2013.

\subsection{Statistical analysis}

The collected data were organized, tabulated and statistically analyzed using Statistical Package of Social Studies (SPSS) version 19. Categorical variables were presented as number and percentages. Differences between categories of each variable between cases and control before and after intervention were statistically analyzed using Monte Carlo Exact test

ISSN 1925-4040 E-ISSN 1925-4059 
(MCET). Differences between cases before and after intervention were tested using Wilcoxon singed ranks test $(Z)$. For numerical variables, the mean and standard deviation were calculated. Differences of mean value between cases and control were statistically tested using student's $t$ test. On the other hand, differences of mean values before and after intervention were tested using paired $t$ test. Pearson's correlation coefficient $r$ was calculated to test the association between proper nutrition and sound practice of sports scores and results of investigations for blood glucose and glycosylated hemoglobin. The level of significance was adopted at $p$ $<.05$.

\section{RESULTS}

Table 1 displayed the socio-demographic characteristics of the studied subjects. As noticed in the table, in the cases group, $50.0 \%$ were females and the other was males. The majority of participants $(90.0 \%)$ have a preparatory level of education. The highest percentage $(78.3 \%)$ of participants lived in rural area. There was no statistical significant difference between cases and control groups regarding gender, child's age, educational level, duration of illness, residence, father's education and mother's education where $p=.271$, $1.000, .506, .683, .522, .475, .525$ respectively.

Table 1. Distribution of socio-demographic characteristics of studied subjects

\begin{tabular}{|c|c|c|c|c|c|c|}
\hline \multirow{2}{*}{ Variables } & \multicolumn{2}{|c|}{ Cases $(n=60)$} & \multicolumn{2}{|c|}{ Control $(n=60)$} & \multirow{2}{*}{$\chi^{2}$} & \multirow{2}{*}{$p$} \\
\hline & $\mathbf{n}$ & $\%$ & n & $\%$ & & \\
\hline \multicolumn{7}{|l|}{ Gender } \\
\hline Males & 30 & 50.0 & 36 & 60.0 & \multirow[t]{2}{*}{1.212} & \multirow[t]{2}{*}{.271} \\
\hline Females & 30 & 50.0 & 24 & 40.0 & & \\
\hline \multicolumn{7}{|l|}{ Child's age } \\
\hline $12-$ & 18 & 30.0 & 18 & 30.0 & \multirow{3}{*}{0.000} & \multirow{3}{*}{1.000} \\
\hline 13- & 19 & 31.7 & 19 & 31.7 & & \\
\hline $14-$ & 23 & 38.3 & 23 & 38.3 & & \\
\hline \multicolumn{7}{|l|}{ Educational Level } \\
\hline Primary & 6 & 10.0 & 10.0 & 4 & \multirow[t]{2}{*}{0.436} & \multirow[t]{2}{*}{.506} \\
\hline Preparatory & 54 & 90.0 & 58 & 93.3 & & \\
\hline \multicolumn{7}{|l|}{ Duration of illness in years } \\
\hline$<1$ & 29 & 48.3 & 26 & 43.3 & \multirow{3}{*}{0.764} & \multirow{3}{*}{.683} \\
\hline $1-$ & 25 & 41.7 & 25 & 41.7 & & \\
\hline 3- & 6 & 10.0 & 9 & 15.0 & & \\
\hline \multicolumn{7}{|l|}{ Residence } \\
\hline Rural & 47 & 78.3 & 44 & 73.3 & \multirow[t]{2}{*}{0.409} & \multirow[t]{2}{*}{.522} \\
\hline Urban & 13 & 21.7 & 16 & 26.7 & & \\
\hline \multicolumn{7}{|l|}{ Fathers' education } \\
\hline Illiterate \& Read and write & 21 & 35.0 & 12 & 20.0 & \multirow{4}{*}{ MCET } & \multirow{4}{*}{.475} \\
\hline Elementary education & 13 & 21.7 & 14 & 23.3 & & \\
\hline Technical education & 22 & 36.7 & 31 & 51.7 & & \\
\hline University education & 4 & 6.7 & 3 & 5.0 & & \\
\hline \multicolumn{7}{|l|}{ Mother's education } \\
\hline Illiterate \& Read and write & 24 & 40.0 & 18 & 30.0 & \multirow{4}{*}{ MCET } & \multirow{4}{*}{.525} \\
\hline Elementary education & 18 & 30.0 & 28 & 46.7 & & \\
\hline Technical education & 16 & 26.7 & 12 & 20.0 & & \\
\hline University education & 2 & 3.3 & 2 & 3.3 & & \\
\hline
\end{tabular}

Note. MCET = Monte Carlo Exact Test.

\subsection{Hypothesis one}

Table 2 showed comparison of cases group before and after intervention in relation to care for feet and nails items (item1, item4, item5, item6, item7, item8, item9, item10, item11, item13, item14, item15, item16 and item17), there was sta- tistical significant difference between cases group before and after intervention where $p 2=(4.900,4.854,5.054,4.877$, $4.415,4.465,4.992,4.895,4.578,4.779,4.611,4.492,4.510$, $4.664,4.988,4.125,4.731)$ respectively. 
Table 2. Distribution of cases in relation to care for feet and nails before and after intervention

\begin{tabular}{|c|c|c|c|c|c|c|c|c|c|c|c|c|c|c|}
\hline \multirow{3}{*}{ Care of feet and nails } & \multicolumn{6}{|c|}{ Cases Before $(n=28)$} & \multicolumn{6}{|c|}{ Cases After $(n=60)$} & \multirow{3}{*}{$p 1$} & \multirow{3}{*}{$\begin{array}{l}\mathrm{Z} \\
p 2\end{array}$} \\
\hline & \multicolumn{2}{|c|}{ NP } & \multicolumn{2}{|l|}{$\mathbf{P}$} & \multicolumn{2}{|c|}{ PW/E } & \multicolumn{2}{|c|}{ NP } & \multicolumn{2}{|c|}{$\mathbf{P}$} & \multicolumn{2}{|c|}{ PW/E } & & \\
\hline & $\mathbf{n}$ & $\%$ & $\mathbf{n}$ & $\%$ & $\mathbf{n}$ & $\%$ & n & $\%$ & $\mathbf{n}$ & $\%$ & n & $\%$ & & \\
\hline Examine feet well daily & & & & & & & & & & & & & & \\
\hline $\begin{array}{l}\text { looking for scratches, } \\
\text { cuts, sores or redness }\end{array}$ & 12 & 42.9 & 14 & 50.0 & 2 & 7.1 & 0 & 0.0 & 1 & 1.7 & 59 & 98.3 & $.001 *$ & $4.90^{*}$ \\
\hline $\begin{array}{l}\text { Always check between } \\
\text { your toes }\end{array}$ & 18 & 64.3 & 10 & 35.7 & 0 & 0.0 & 0 & 0.0 & 0 & 0.0 & 60 & 100 & $.001 *$ & $4.85^{*}$ \\
\hline $\begin{array}{l}\text { Wash feet daily and a } \\
\text { good-dry }\end{array}$ & 13 & 46.4 & 11 & 39.3 & 4 & 14.3 & 0 & 0.0 & 6 & 10.0 & 54 & 90.0 & $.001 *$ & $5.05^{*}$ \\
\hline $\begin{array}{l}\text { Avoid use of very hot or } \\
\text { cold water }\end{array}$ & 21 & 75.0 & 6 & 21.4 & 1 & 3.6 & 0 & 0.0 & 2 & 3.4 & 58 & 96.6 & $.001 *$ & $4.88^{*}$ \\
\hline $\begin{array}{l}\text { Avoid inundation of the } \\
\text { feet in the water for a } \\
\text { long time }\end{array}$ & 22 & 78.6 & 6 & 21.4 & 0 & 0.0 & 1 & 1.7 & 4 & 6.7 & 55 & 91.6 & $.001 *$ & $4.42 *$ \\
\hline $\begin{array}{l}\text { Nails cut carefully to } \\
\text { avoid leaving a sharp } \\
\text { edge and cut fingernails } \\
\text { in a circular fashion }\end{array}$ & 11 & 39.3 & 14 & 50.0 & 3 & 10.7 & 1 & 1.7 & 1 & 1.7 & 58 & 96.7 & $.001 *$ & $4.47^{*}$ \\
\hline $\begin{array}{l}\text { Soften the nails using } \\
\text { nail file for that }\end{array}$ & 19 & 67.9 & 9 & 32.1 & 0 & 0.0 & 0 & 0.0 & 2 & 3.3 & 58 & 96.7 & $.001 *$ & $4.99 *$ \\
\hline $\begin{array}{l}\text { Keen to massage the feet } \\
\text { and legs from time to } \\
\text { time }\end{array}$ & 18 & 64.3 & 10 & 35.7 & 0 & 0.0 & 1 & 1.7 & 1 & 1.7 & 58 & 96.7 & $.001 *$ & $4.89 *$ \\
\hline $\begin{array}{l}\text { Use chemicals to remove } \\
\text { excess skin }\end{array}$ & 19 & 67.9 & 8 & 28.6 & 1 & 3.6 & 1 & 1.7 & 2 & 3.3 & 57 & 95.0 & $.001 *$ & $4.58 *$ \\
\hline $\begin{array}{l}\text { Do not use bond to } \\
\text { sticker on feet }\end{array}$ & 12 & 42.9 & 14 & 50.0 & 2 & 7.1 & 0 & 0.0 & 2 & 3.3 & 58 & 96.7 & $.001 *$ & $4.78^{*}$ \\
\hline $\begin{array}{l}\text { Use a cream to soften } \\
\text { areas of hard skin, but } \\
\text { not between the fingers }\end{array}$ & 17 & 60.7 & 10 & 35.7 & 1 & 3.6 & 1 & 1.7 & 4 & 6.7 & 55 & 91.6 & $.001 *$ & $4.61^{*}$ \\
\hline Avoid walking barefoot & 17 & 60.7 & 7 & 25.0 & 4 & 14.3 & 1 & 1.7 & 3 & 5.0 & 56 & 93.3 & $.001 *$ & $4.49 *$ \\
\hline $\begin{array}{l}\text { Using comfortable shoes } \\
\text { (made of soft material) } \\
\text { or not tight or large }\end{array}$ & 16 & 57.1 & 11 & 39.3 & 1 & 3.6 & 0 & 0.0 & 4 & 6.7 & 56 & 93.3 & $.001 *$ & $4.51^{*}$ \\
\hline $\begin{array}{l}\text { Examine the shoes well } \\
\text { to detect the presence of } \\
\text { any foreign body inside } \\
\text { it. }\end{array}$ & 20 & 71.4 & 8 & 28.6 & 0 & 0.0 & 0 & 0.0 & 2 & 3.3 & 58 & 96.7 & $.001 *$ & $4.66^{*}$ \\
\hline $\begin{array}{l}\text { Make sure the shoes dry } \\
\text { from inside }\end{array}$ & 20 & 71.4 & 7 & 25.0 & 1 & 3.6 & 1 & 1.7 & 0 & 0.0 & 59 & 98.3 & $.001 *$ & $4.99 *$ \\
\hline $\begin{array}{l}\text { Have shoes with broad } \\
\text { front \& heel }\end{array}$ & 20 & 71.4 & 8 & 28.6 & 0 & 0.0 & 3 & 5.0 & 4 & 6.7 & 53 & 85.3 & $.001 *$ & $4.3^{*}$ \\
\hline $\begin{array}{l}\text { The use of woolen socks } \\
\text { in winter and cotton in } \\
\text { the summer }\end{array}$ & 18 & 64.3 & 10 & 35.7 & 0 & 0.0 & 1 & 1.7 & 4 & 6.7 & 55 & 91.6 & $.001 *$ & $4.73^{*}$ \\
\hline
\end{tabular}

*Significant $p<.001 ; p 1$ =comparison of cases after versus control after (Monte Carlo Exact test); $p 2$ = comparison of cases before and after (Wilcoxon singed ranks test); $\mathrm{P}=$ Performed; $\mathrm{NP}=$ Not performed, $\mathrm{PW} / \mathrm{E}=$ Performed well/excellent.

Table 3 and Figures 1-3 illustrated comparison of total score of items of diabetes care before and after intervention. As noticed from the table and figures, there was statistical significant improvement in analysis of urine for detection of acetone and sugar, care of feet and nails, blood glucose monitoring, nutritional practices and practicing of exercise of cases group after intervention $(29.90+1.48,64.25+2.81$, $36.35+2.44,10.88+1.45$ and $7.62+1.14$, respectively) compared with control group $(11.24+0.68,23.21+1.37$, $17.63+2.11,5.28+1.37$ and $4.25+1.03$, respectively).

\subsection{Hypothesis two and three}

Table 4 and Figures 4-6 showed comparison of total score of items of results of investigations before and after intervention. As shown from the table and figures, there was statistical significant reduction in fasting blood sugar, Post prandial blood sugar and glycosylated hemoglobin level of cases group after intervention $(120.57+29.13,165.57+$ 29.13 and $7.08+1.56$, respectively) compared with cases group before intervention $(166.37+27.66,232.80+57.02$ and $9.61+1.94$, respectively). 
Table 3. Comparison of total score of items of diabetes care before and after intervention

\begin{tabular}{|c|c|c|c|c|}
\hline \multirow{2}{*}{ Variables } & \multirow{2}{*}{$\begin{array}{l}\text { Cases } \\
\text { (Mean } \pm \text { SD) }\end{array}$} & Control & $t$ & $p$ \\
\hline & & \multicolumn{2}{|l|}{$($ Mean \pm SD) } & \\
\hline \multicolumn{5}{|c|}{ Analysis of urine for detection of acetone and sugar } \\
\hline Before intervention & $16.05+3.27$ & $13.46+1.88$ & 4.265 & $.001^{*}$ \\
\hline After intervention & $29.90+1.48$ & $11.24+0.68$ & 84.133 & $.001^{*}$ \\
\hline$t$ & 24.428 & 6.781 & & \\
\hline$p$ & $.001^{*}$ & $.001 *$ & & \\
\hline \multicolumn{5}{|l|}{ Care of feet and nails } \\
\hline Before intervention & $24.21+3.22$ & $24.36+2.13$ & 0.196 & .846 \\
\hline After intervention & $64.25+2.81$ & $23.21+1.37$ & 73.201 & $.001 *$ \\
\hline$t$ & 41.985 & 2.458 & & \\
\hline$p$ & $.001^{*}$ & $.021 *$ & & \\
\hline \multicolumn{5}{|c|}{ Blood glucose monitoring } \\
\hline Before intervention & $16.74+2.80$ & $18.00+2.22$ & 1.875 & .066 \\
\hline After intervention & $36.35+2.44$ & $17.63+2.11$ & 34.429 & $.001^{*}$ \\
\hline$t$ & 26.582 & 0.704 & & \\
\hline$p$ & $.001^{*}$ & .488 & & \\
\hline \multicolumn{5}{|l|}{ Nutritional practices } \\
\hline Before intervention & $5.73+1.55$ & $5.78+1.26$ & 0.194 & .847 \\
\hline After intervention & $10.88+1.45$ & $5.28+1.37$ & 21.764 & $.001 *$ \\
\hline$t$ & 22.735 & 2.750 & & \\
\hline$p$ & $.001^{*}$ & $.008^{*}$ & & \\
\hline \multicolumn{5}{|l|}{ Practicing of exercise } \\
\hline Before intervention & $4.18+0.92$ & $4.46+1.10$ & 1.032 & .307 \\
\hline After intervention & $7.62+1.14$ & $4.25+1.03$ & 12.580 & $.001^{*}$ \\
\hline$t$ & 15.338 & 0.632 & & \\
\hline$p$ & $.001 *$ & .534 & & \\
\hline
\end{tabular}

*Significant

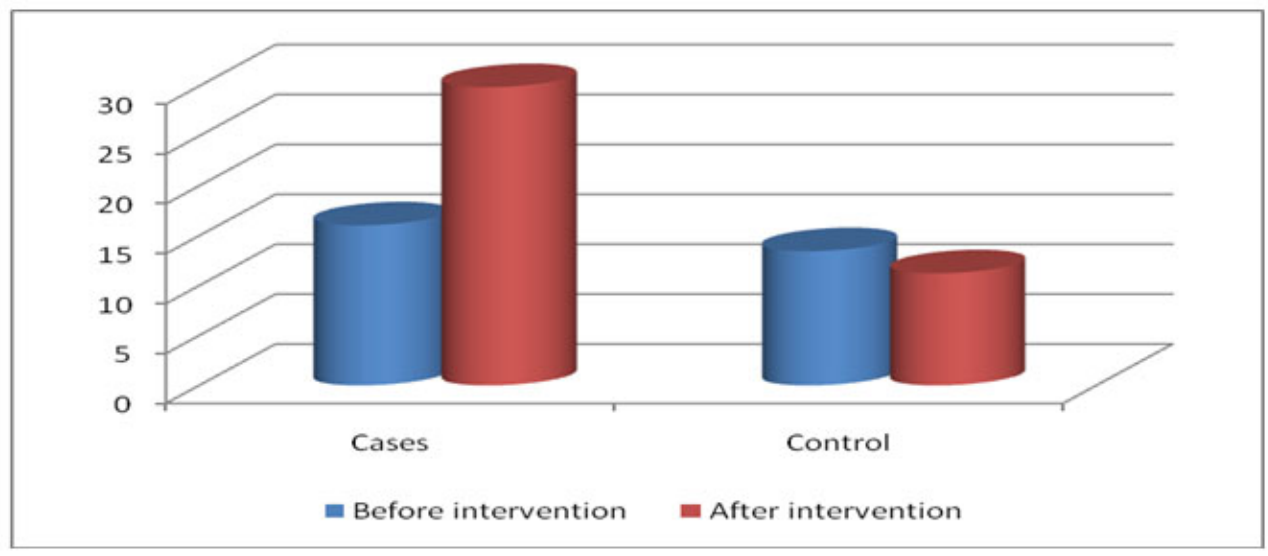

Figure 1. Comparison of total score of analysis of urine before and after intervention among studied diabetic subjects

Table 5 demonstrated correlation between results of investigations and total score of nutritional practices before and after intervention. As noticed from the table, there was no statistical significant difference between total score of nutritional practices and fasting blood sugar, post prandial blood sugar and glycosylated hemoglobin level before intervention Published by Sciedu Press where $p=(.197, .516$ and .960 , respectively $)$. While there was statistical significant difference between total score of nutritional practices and fasting blood sugar, post prandial blood sugar and glycosylated hemoglobin level after intervention where $p=.001$. 


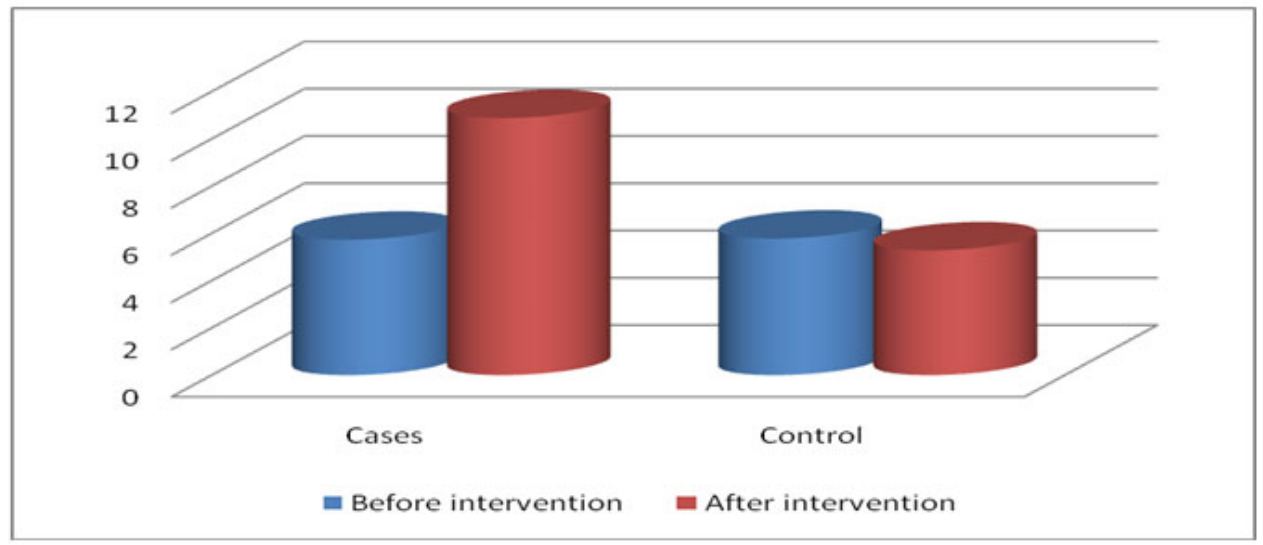

Figure 2. Comparison of total score of nutritional practices before and after intervention among studied diabetic subjects

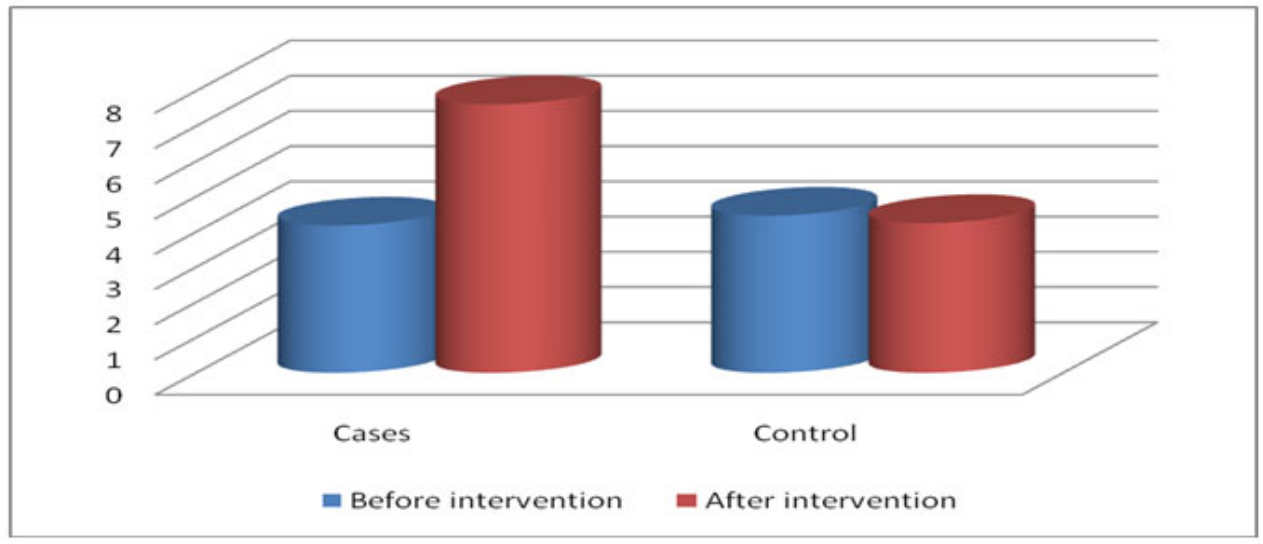

Figure 3. Comparison of total score of practicing exercise before and after intervention among studied diabetic subjects

Table 4. Comparison of total score of investigations before and after intervention

\begin{tabular}{lllll}
\hline Variables & Cases & Control & $\boldsymbol{t}$ & $\boldsymbol{p}$ \\
\hline Fasting blood sugar & $($ Mean \pm SD) & $($ Mean \pm SD) & & \\
Before intervention & $166.37+27.66$ & $211.25+46.50$ & 6.246 & $.001^{*}$ \\
After intervention & $120.57+29.13$ & $182.57+47.37$ & 8.636 & $.001^{*}$ \\
$t$ & 10.428 & 6.035 & & \\
$p$ & $.001^{*}$ & $.001^{*}$ & & \\
Post prandial blood sugar & & & & \\
$\quad$ Before intervention & $232.80+57.02$ & $313.68+84.15$ & 6.136 & $.001^{*}$ \\
After intervention & $165.57+29.13$ & $283.67+95.51$ & 8.846 & $.001^{*}$ \\
$t$ & 8.44 & 4.488 & & \\
$p$ & $.001^{*}$ & $.001 *$ & & \\
Glycosylated hemoglobin level & & & & \\
Before intervention & $9.61+1.94$ & $11.91+2.15$ & 6.163 & $.001^{*}$ \\
After intervention & $7.08+1.56$ & $10.64+2.68$ & 8.878 & $.001^{*}$ \\
$t$ & 9.231 & 4.173 & & \\
$p$ & $.001^{*}$ & $.001 *$ & & \\
\hline
\end{tabular}

*Significant 


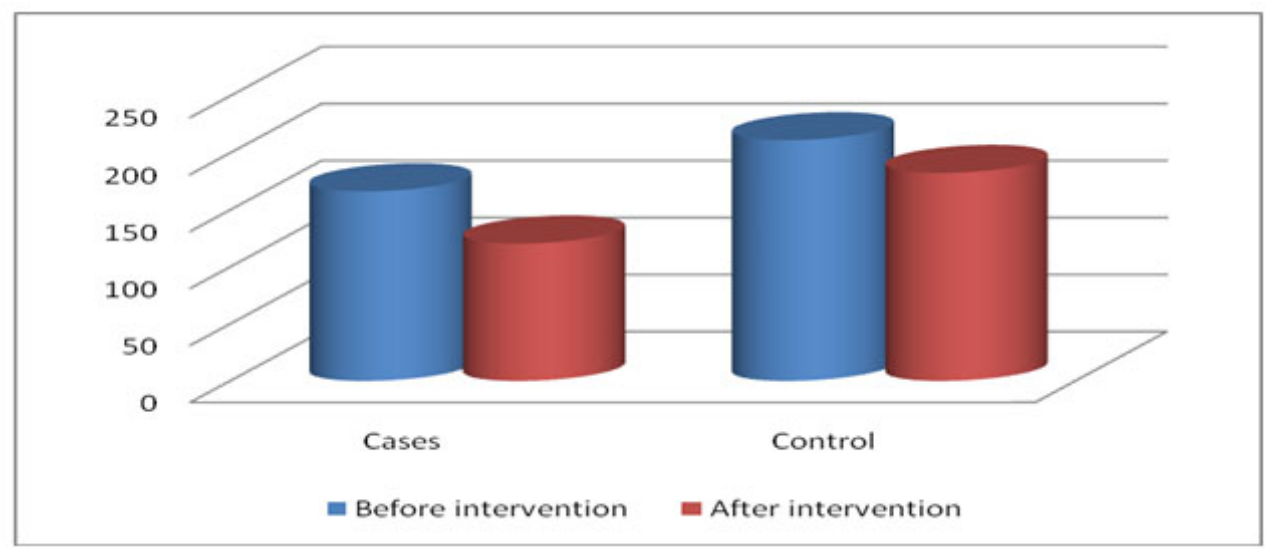

Figure 4. Comparison of mean fasting blood sugar before and after intervention among studied diabetic subjects

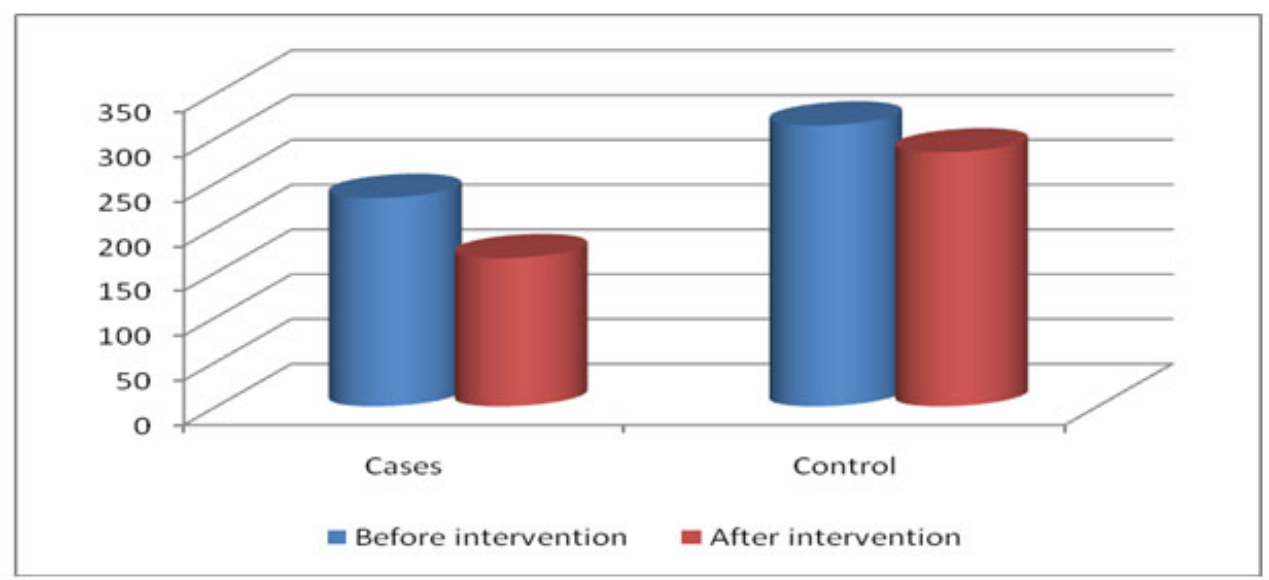

Figure 5. Comparison of mean value of post-prandial blood sugar before and after intervention among studied diabetic subjects

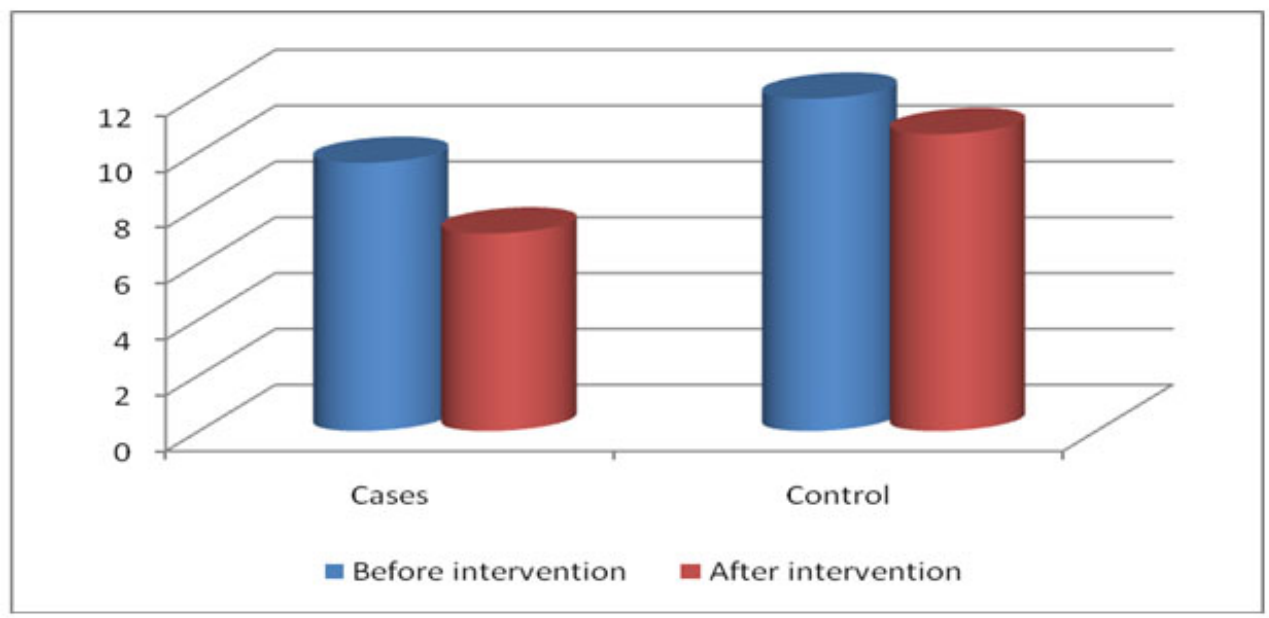

Figure 6. Comparison of mean value of glycosylated hemoglobin before and after intervention among studied diabetic subjects 
Table 5. Correlation between results of investigations and total score of nutritional practices before and after intervention

\begin{tabular}{llllll}
\hline \multirow{2}{*}{ Investigations } & \multicolumn{2}{l}{ Nutritional practices score Before } & & \multicolumn{2}{c}{ Nutritional practices score after } \\
\cline { 2 - 3 } \cline { 5 - 6 } & $\boldsymbol{r}$ & $\boldsymbol{p}$ & .197 & -0.570 & \multicolumn{2}{c}{$.001^{*}$} \\
\hline Fasting blood sugar & 0.117 & .516 & -0.541 & $.001^{*}$ \\
Post prandial blood sugar & 0.060 & .960 & -0.852 & $.001^{*}$ \\
Glycosylated hemoglobin level & -0.005 & & & \\
\hline
\end{tabular}

*Significant

Table 6 illustrated correlation between results of investigations and total score of practicing of exercise before and after intervention. As noticed from the table, there was no statistical significant difference between total score of practicing of exercise and fasting blood sugar, post prandial blood sugar and glycosylated hemoglobin level before intervention where $p=(.940, .889$ and .692 , respectively $)$. On the other hand, there was statistical significant difference between total score of practicing of exercise and fasting blood sugar, post prandial blood sugar and glycosylated hemoglobin level before intervention where $p=.001$.

Table 6. Correlation between results of investigations and total score of practicing of exercise before intervention after intervention

\begin{tabular}{|c|c|c|c|c|}
\hline \multirow{2}{*}{ Investigations } & \multicolumn{2}{|c|}{ Practicing of exercise score before } & \multicolumn{2}{|c|}{ Practicing of exercise score After } \\
\hline & $r$ & $p$ & $r$ & $p$ \\
\hline Fasting blood sugar & -0.010 & .940 & -0.493 & $.001 *$ \\
\hline Post prandial blood sugar & -0.019 & .889 & -0.569 & $.001^{*}$ \\
\hline Glycosylated hemoglobin level & 0.054 & .692 & -0.545 & $.001 *$ \\
\hline
\end{tabular}

*Significant

\section{Discussion}

Diabetes mellitus is a chronic disease which needs continuous care all over the diabetic patient life especially at adolescent age. ${ }^{[29]}$ Self-management refers to the extent to which the person adhere to prescribed diet restriction, physical activities requirement, medication administration, testing blood sugar level and foot care. ${ }^{[30]}$ Using audio-visual materials to teach psychomotor skills via role modeling is proven to be effective. ${ }^{[31]}$ When using video materials, an opportunity exists for patients to identify with persons portrayed and the tasks they are performing. ${ }^{[32]}$

The aim of this study was to determine the effect of using High-definition video technology on improving diabetes management.

Regarding feet and nails care practices and skills among the studied group after intervention and cases group before and after intervention, the finding of this study revealed statistical improvement in practices and skills of cases group than control group after intervention and there was statistically significant difference between pre and post intervention phases in the cases group (see Table 2). The finding of the present study is in the same line with the study was carried out by Goetti $\mathrm{K}^{[20]}$ in Canada who examined the effect of a teaching video on improving of foot care compliance for persons with type 2 diabetes, and reported that, a large increase in perceived knowledge of foot care after viewing the video. Also, Gerber $\mathrm{B}$ et al. ${ }^{[33]}$ have proposed the implementation and evaluation of a low literacy diabetes education computer multimedia application that was focused on computer-based multimedia in clinical settings, and have shown the value of this tool in effectively teaching about diabetes-related complications, especially for patients with low literacy levels. In addition, the result was consistent with Rymers $\mathrm{I}^{[34]}$ who concluded that the DVD/Poster/Written material approach worked well on intervention group in regards to changing their knowledge base of foot care. The results have proved that multimedia can be a useful method to provide the fundamental and high profile skills. Those results may be contributed to prove the effect of using video technology in teaching.

Concerning comparison of total score of items of diabetes care before and after intervention, the finding of the present study revealed statistical significant improvement in practices and skills regarding analysis of urine for detection of acetone and sugar, care of feet and nails, blood glucose monitoring, nutritional practices and practicing of exercise (see Table 3, Figures 1-3). This finding is similar to what was reported by Abdel Megeid F et al. ${ }^{[35]}$ who examined the effect of health 
education intervention on improving knowledge, attitude and practices of mothers of insulin dependent diabetes mellitus, and reported that there was a statistical significance increase in the mothers' knowledge as regards the diabetic complications, long life treatment of diabetes and regulation of sweets and carbohydrate intake as rice and macaroni.

Also, the finding of the present study is supported by Otero LM et al. ${ }^{[36]}$ findings who studied knowledge of diabetic patients about their disease before and after implementing a diabetes education program, and reported that increased knowledge of patients with diabetes after a 12-monthes' program of diabetes education. Moreover, the present finding is supported by Xuereb G et al. ${ }^{[37]}$ who stated that improved knowledge of health care professionals is a key to the successful implementation of the protocol and improved quality of care and there was a positive effect on increasing cases group's score level of practices and skills related to items of diabetes care. In addition, the present study results in congruence with Abdel Megeid F et al. ${ }^{[35]}$ who studied the effect of health education intervention on improving knowledge, attitude and practices of mothers of insulin dependent diabetes, and indicated that the health program significantly increased the mother health knowledge about diabetes complications decreased dietary carbohydrates and sweets, increased their attitude towards urine follow up and significantly change the practice of daily urine and blood glucose screening. Those results may be contributed to prove the effect of using health education intervention-assisted technology as a useful method in improving knowledge, attitude and practices of diabetic children.

Regarding comparison of total score of items of results of investigations before and after intervention, the finding of this study revealed significant reduction in fasting blood sugar, post prandial blood sugar and glycosylated hemoglobin level of cases group after intervention compared with cases group before intervention (see Table 4 and Figures 4-6). This finding is similar to the results of the study carried out by Davis RM et al. ${ }^{[38]}$ that studied the effect of using Tele Health in improving diabetes self-management in an Underserved Community, and reported that there was a significant reduction in glycated hemoglobin in the Diabetes Tele care group for baseline to 6 and 12 months compared with usual care. Also, this result is in accordance with the studies carried out by Baghyani-Moghadam MH et al. ${ }^{[39-43]}$ who reported that there was significant reduction in the mean serum HBAIC concentrations after the intervention period and also, reduction in mean serum of fasting and post prandial blood sugar concentrations after the intervention period. This means that implementation of intervention was effective and brought improvements in health outcomes.
Regarding correlation between results of investigations and total score of nutritional practices before and after intervention, the finding of the present study indicated that there was no statistical significant difference between total score of nutritional practices and results of investigations before intervention. Whereas, statistical significant difference between total score of nutritional practices and results of investigations after intervention (see Table 5). This finding is similar to what was reported by Norris SL et al. ${ }^{[44]}$ who examined the effect of self-management education for adults with type 2 diabetes: a meta-analysis of on glycemic control and reviewed 31 studies and, and concluded that Glycosylated hemoglobin (A1C) levels are improved by diabetes self-management education. Also, they added that the provision of nutrition and health programs targeted toward diabetes education were effective in the improvement of diabetes knowledge and A1C scores, and should therefore be an integral component of diabetes management programs. Those results may be due to the proper practice after health education intervention-assisted technology.

Also, the finding of the present study is supported by Burnett $\mathrm{SM}^{[45]}$ findings that studied the effect of nutrition and diabetes education program on improving A1C knowledge and A1C blood levels, and indicated that nutrition and diabetes education program significantly and favorably improved both knowledge of A1C and blood levels of A1C. These findings suggest that nutrition and diabetes education programs assisting older adults in improving management of their diabetes. This finding is similar to Mogra $\mathrm{R}$ et al. ${ }^{[46]}$ findings who examined the impact of nutrition counseling on blood glucose level of patients suffering from non insulin dependent diabetes mellitus, and mentioned that the mean fasting blood glucose $120-140 \mathrm{mg} / \mathrm{dl}$ before counseling was $127.66 \pm 0.85$ $\mathrm{mg} / \mathrm{dl}$ and $122.22 \pm 0.88 \mathrm{mg} / \mathrm{dl}$ after ten days of counseling. The mean fasting blood glucose level after thirteen days of counseling was reduced to $120.88 \pm 0.85 \mathrm{mg} / \mathrm{dl}$ from 127.66 $\pm 0.85 \mathrm{mg} / \mathrm{dl}$, which is statistically significant $(p<.05)$. In addition, the finding of the present study is supported by ${ }^{[47]}$ who studied the impact of nutrition education on improving metabolic outcomes among older adults with diabetes mellitus, and observed increased in total knowledge scores and greater decrease in fasting plasma glucose levels among diabetic patients after nutrition education. The results have proved that self-management education -assisted technology regarding nutritional practices led to improvement in children's laboratory results and nutritional practices.

Concerning correlation between results of investigations and total score of practicing of exercise before and after intervention, the results revealed that there was no statistical significant difference between total score of nutritional prac- 
tices and results of investigations before intervention. Also, there was statistical significant difference between total score of practicing of exercise and results of investigations after intervention (see Table 6). This finding is similar to ${ }^{[48]}$ finding who studied a multifactorial intervention to enhance adherence to medications and disease-related knowledge in Type 2 diabetic patients in southern Punjab, Pakistan, and concluded that increase in knowledge regarding dietary restrictions and exercise resulted in improvement in glycemic control as reported in other interventions studies aimed at increasing exercise combined with dietary restrictions. ${ }^{[49]}$

Similar finding was conducted by Hordern MD et al. ${ }^{[50]}$ who studied exercise prescription for patients with type 2 diabetes and pre-diabetes: A position statement from Exercise and Sport Science Australia, and reported that the moderate to vigorous intensity group had a greater $(0.5 \%)$ absolute reduction in HbAlc compared to a smaller reduction $(0.2 \%)$ in the low to moderate intensity group. Also, he added that the majority of studies in patients with pre-diabetes have shown improvements in glycaemic control and/or reduction in the incidence of T2DM from around $210 \mathrm{~min} /$ week or more of exercise ${ }^{[51-54]}$ In addition, the present finding is supported by ${ }^{[55]}$ finding who examined the influence of aerobic treadmill exercise on blood glucose homeostasis in non insulin dependent diabetes mellitus patients, and observed the significant decrease in postprandial blood sugar $(44.4 \mathrm{mg} \%$ for the study group and $32.2 \mathrm{mg} \%$ for the control group) with a significant inter group difference $(P<.05)$ was observed. The mean decrease in fasting blood sugar $(39.4 \mathrm{mg} \%$ for the study group and $27.4 \mathrm{mg} \%$ for the control group), with a marginal inter group difference $(P<.05)$ was observed. The treadmill exercise was found to be a definite tool in addition to drug and diet in glycemic control. Those results could be attributed to prove that self-management educationassisted technology regarding practicing of exercise led to improvement in children's laboratory results and exercising.

\section{Conclusions}

The implementation of teaching-assisted High-Definition Video Technology has succeeded in achieving significant improvement in children's diabetes management practices skills of cases group. This improvement in children's diabetes management practices skills led to improvement in children's laboratory results and exercising. Regarding the control group, there was almost no change in children's diabetes management practices skills. Hence, it was concluded that the results provide important evidence that the use of High-Definition Video as a valuable teaching tool to communicate best practice information in a consistent way.

\section{Recommendation}

Implementation of teaching-assisted High-definition video technology in different settings for different groups of children is recommended.

\section{CONFlicts OF INTEREST Disclosure}

The authors declare that there is no conflict of interest statement.

\section{REFERENCES}

[1] Adolfsson ET, Starrin B, Smide B, et al. Type 2 Diabetic Patients' Experiences of Two Different Educational Approaches-A Qualitative Study. International Journal of Nursing Studies. 2008; 45(7): 986-994. PMid:17822705 http://dx.doi.org/10.1016/j.ijn urstu.2007.07.007

[2] Wild S, Roglic G, Green A, et al. Global Prevalence of Diabetes: Estimates for The Year 2000 and Projections for 2030. Diabetes Care. 2004; 27: 1047-1053. http://dx.doi.org/10.2337/diacare .27 .5 .1047

[3] Centers for Disease Control and Prevention. Chronic diseases and health promotion. 2009. Available from: http://www.cdc.gov/ chronicdisease/overview/index.htm

[4] Vinicor F. The Future of Diabetes: What is There Besides New Medicines? Clin Diabetes. 2004; 22(2): 94-6. Available from: http://www.jdst.org/November2007/pdf/VOL-1 -6-REV1-BROWN.pdf http://dx.doi.org/10.2337/diaclin .22 .2 .94

[5] Schilling S, Grey M, Knafl K. The concept of self-management of type 1 diabetes in children and adolescents: an evolutionary concept analysis. Journal of Advanced Nursing. 2002; 37(1): 87-99.
Available from: http://www.sciencepub.net/nature/ns0912 1025_7915ns0912_180_189.pdf PMid:11784402 http://dx.d oi.org/10.1046/j.1365-2648.2002.02061.x

[6] US Department of Health and Human Services, Healthy People.gov. With Understanding and Improving Health and Objectives for Improving Health. 2000. Available from: http: //www.healthypeo ple.gov/document/html/volume1/11healthcom.htm

[7] Ball W, Bindler C, Cowem J. Child Health Nursing: Parenting with Children and Families. 2nd ed. New York: Pearson Co., 1281-1300.

[8] National Institute of Diabetes and Digestive and Kidney disease. 2010. Available from: http://www.niddk, nih.gov

[9] Ismail H. Self-rated Health and Factors Influencing Responses among Young Egyptian Type 1 Diabetes Patients. BMC Public Health. 2011; (11): 216. PMid:21473776 http://dx.doi.org/10.1186/147 1-2458-11-216

[10] Leila R. High in Sugar, Low in Priority. Al-Ahram Weekly. Egypt. 2007.

[11] Jackson CL, Bolen S, Brancati FL, et al. A Systematic Review of Interactive Computer Assisted Technology in Diabetic Care: interactive information technology in diabetic care. Journal of Gen- 
eral Internal Medicine. 2005; 21: 105-109. Available from: http: //knowledgetranslation.ca/sysrev/articles/project

[12] Balas EA, Krishna S, Kretschmer RA, et al. Computerized knowledge management in diabetes care. Medical Care. 2004; 42: 610-621. Available from: http://knowledgetranslation.ca/sysrev/a rticles/project PMid:15167329 http://dx.doi.org/10.10 97/01.mlr.0000128008.12117.f8

[13] Durso SC, Wendel I, Letzt AM, et al. Older Adults Using Cellular Telephones for Diabetes Management: a pilot study. Medsurg Nursing. 2003; 12: 313-317. Available from: http://knowledgetrans lation.ca/sysrev/articles/project PMid:14608688

[14] Bellazzi R, Arcelloni M, Bensa G, et al. Design, Methods, and Evaluation Directions of a Multi-Access Service For the Management of Diabetes Mellitus Patients. Diabetes Technology and Therapeutics. 2003; 5: 621-629. Available from: http://knowledgetrans lation.ca/sysrev/articles/project PMid: 14511417 http: //dx.doi.org/10.1089/152091503322250640

[15] McIlhenny CV, Guzic BL, Knee DR, et al. Using Technology to Deliver Healthcare Education to Rural Patients Rural and Remote Health. 2011; 11: 1798 .

[16] Sandham AW, Lehmann DE, Diaz ZM, et al. Electrical and Computer Technology for Effective Diabetes Management and Treatment. Hindawi Publishing Corporation. Journal of Electrical and Computer Engineering. 2011. Available from: http://downloads .hindawi . com/journals/jece/2011/289359.pdf

[17] Moshe P, Tadej B. ATTD 2011 Year Book: Advanced Technologies and Treatments for Diabetes. Published by John Wiley \& Sons Ltd. 2012. Available from: http://publications.theseus.fi/bi tstream/handle/10024/53118/Ayodele_Richards_Kralli nger_Julia_Mori_Paulo.pdf?sequence $=1$

[18] Topiwala S. Diabetes. 2012. Available from: http://www.nlm.ni h.gov/medlineplus/ency/article/001214.htm

[19] Nooriafshar M. Technology in Diabetes Management. ASIAN JOURNAL OF NATURAL \& APPLIED SCIENCES. 2012; 3(1). Available from: http://www.ajsc.leena-luna.co.jp/AJSCPDFs/

[20] Goetti K. Foot Care for Persons with Type 2 Diabetes: Can a teaching video improve compliance? Wound Care Canada. 2005; 3(2). Available from: http://Cawc.net/images/uploads/wcc/3-c -gotti.pdf

[21] Smart C, Aslander-van Vliet E, Waldron S. Nutritional management in children and adolescents with diabetes. ISPAD Clinical Practice Consensus Guidelines 2009 Compendium. Pediatric Diabetes. 2009; 10(Suppl. 12): 100-117. PMid:19754622 http://dx.doi.org/10. 1111/j.1399-5448.2009.00572.x

[22] Robertson K, Adolfsson P, Riddell M, et al. Exercise in children and adolescents with diabetes. ISPAD Clinical Practice Consensus Guidelines 2009 Compendium. Pediatric Diabetes. 2009; 10(Suppl. 12): 154-168. PMid:19754626 http://dx.doi.org/10.1111/j .1399-5448.2009.00567.x

[23] Patel N, Knight D. Clinical Practical Procedures for Junior Doctors. Churchill Livingstone: Elsevier; 2009.

[24] Pinzur SM, Slovenkai PM, Trepman E, et al. Guidelines for Diabetic Foot Care: Recommendations Endorsed by the Diabetes Committee of the American Orthopaedic Foot and Ankle Society. Foot and Ankle International. 2005; 26(1).

[25] O'Kane M, Pickup J. Self monitoring of blood glucose in diabetes: is it worth it? Ann Clin Biochem. 2009; 46: 273-282. PMid:19454538 http://dx.doi.org/10.1258/acb.2009.009011

[26] Kwame Nkrumah Unversity of Science and Technology. 2011. Available from: http://creativecommons.org/licenses/by-nc/ $3.0 /$

[27] American College of physicians foundation. 2010.
[28] International Diabetes Federation Consultative Section on the Diabetic Foot, Diabetic Foot Society of India, International Working Group on the Diabetic foot and Muhimbili University College of Health Sciences Dares Salaam, Tanzania. Improving Diabetes Foot Care in the Developing World Project. Produced by Video Prasar Mumbai, India. 2005.

[29] Silverstein J, Copeland K, Laffel L, et al. Care of Children and Adolescents with Type1 Diabetes: A statement of the American diabetes Association. Diabetic Care. 2005; 28(11): 86-212. Available from: http://www. jof americanscience.org/journals/ am-sci/am0712/147_8013am0712_1179_1187.pdf

[30] Barker D. Measurement of Disease Specific Social Support in Adolescent with Cystic Fibrosis. 2010; 6: 1-35. Available from: http://www. jof americanscience.org/journals/am -sci/am0712/147_8013am0712_1179_1187.pdf

[31] Rhee MK, Cook CB, EL-Kebbi I, et al. Barriers to Diabetes Education in Urban Patient: Perceptions, Patterns, and Associated Factors. The Diabetes Educator. 2005; 31: 410-417. Available from: http://CSUS-dspace.calstale.edu/bitstream/han dle/10211-9/727/Thesis.pdf

[32] Murphy PW, Chesson AL, Walker L, et al. Comparing the Effectiveness of Video and Written Material for Improving Knowledge among Sleeping Disorder Clinic Patients with Limited Literacy Skills. Southern Medical Journal. 2000; 93: 297-304. Available from: http://CSUS-dspace.calstale.edu/bitstream /handle/10211-9/727/Thesis.pdf

[33] Gerber B, Brodsky IG, Lawless KA, et al. Implementation And Evaluation of A Low Literacy Diabetes Education Computer Multimedia Application. Diabetes Care. 2005; 28: 1574-1580. Available from: http://CSUS-dspace.calstale.edu/bitstream /handle/10211-9/727/Thesis.pdf

[34] Rymers I. Use of Audio-visual Patient Education to Enhance Diabetic Foot Care. Published Master of Science in nursing thesis. California State University. 2010. Available from: http://CSUS-dspace.Ca lstale.edu/bitstream/handle/10211.9/727/Thesis.pdf

[35] Abdel Megeid FY, El-Sayed MM. Health Education Intervention Improves Knowledge, Attitude and Practices of Mothers of Insulin Dependent Diabetes Mellitus. World Applied Sciences Journal. 2012; 17(11): 1398-1404. Available from: http://www-idosi.org/was j17(11) 12/pdf

[36] Otero LM, Zanetti ML, Ogrizio MD. Knowledge of diabetic patients about their disease before and after implementing a diabetes education program. Rev. Latino-am Enfermagem, Março-abril. 2008; 16(2): 231-7. Available from: http://www.idosi.org/wasj/w asj17(11) 12/4.pdf

[37] Xuereb G, Pauline S, Dalip R, et al. Improving Best Practices through Nutrition Education among Caribbean Health Care Professionals Int. J. Diabetes \& Metabolism. 2007; 15: 88-93. Available from: http://www-idosi.org/wasj17(11) 12/pdf

[38] Davis RM, Hitch AD, Salaam MM, et al. Tele Health Improve Diabetes Self-management in an Underserved Community. Diabetes Care. 2010; 33: 1712-1717. Available from: http://care.diabe tesjournals.org/content PMid:20484125 http://dx.doi.o $\mathrm{rg} / 10.2337 / \mathrm{dc} 09-1919$

[39] Baghyani-Moghadam MH, Shafiei F, Haydarneia AR, et al. Efficacy of Basnef Model in controlling of diabetic patients in the city of Yazd. Iran. Indian journal of Community Medicine. 2005; 30(4). Available from: http://medind.nic.in/iaj/pdf

[40] Anderson-Loftin W, Barnet S, Bunn P, et al. Soul food light; culturally competent diabetes education. Diabetes Educ. 2005; 31(4): 555 63. Available from: http://ijfstn.com/completevon1no2/c 
hapter.pdf PMid:16100331 http://dx.doi.org/10.1177/0 145721705278948

[41] Panja S, Starr B, Colleran KM. Patient Knowledge Improves Glycemic Control: Is It Time to Go Back to The Classroom? JInvestig Med. 2005; 53(5): 264-6. Available from: http:// ijfstn.com/completevon1no2/chapter.pdf PMid:16042960 http://dx.doi.org/10.2310/6650.2005.53509

[42] Channon S, Smith VJ, Gregory JW. A Pilot Study of Motivational Interviewing In Adolescents with Diabetes. Arch Dis Child. 2003; 88: 680-683. Available from: http://www.ncbi.nlm.nih.org/pdf PMid:12876161 http://dx.doi.org/10.1136/adc.88.8.680

[43] Assaad-Khalil SH, El Siwy F, Kamel KF, et al. Impact of an educational video film; The Jinn's party on the knowledge, practices and attitudes of school children and adolescents with Type 1 diabetes and their parents. 18th International Diabetes Federation Congress. 2013; August 24-29. Paris. France. Available from: http://www . easd.org/easdwebfiles

[44] Norris SL, Engelgau MM, Narayan KM, et al. Self-management Education for Adults with Type2 Diabetes: a meta-analysis of the effect on glycemic control. Diabetes Care. 2002; 25: 11591171. Available from: http://athenaeum.libs.uga.edu/bit stream/handle/10724/6883/burnett-sarah PMid:12087014 http://dx.doi.org/10.2337/diacare.25.7.1159

[45] Burnett SM. A Nutrition and Diabetes Education Program Improves A1C Knowledge and A1C Blood Levels. Published Master of Science Thesis. Georgia University. 2013. Available from: http://athenaeum.libs.uga.edu/bitstream/handl e/10724/6883/burnett-sarah

[46] Mogra R, Arora A. Impact of Nutrition Counseling on Blood Glucose Level of Patients Suffering from Non Insulin Dependent Diabetes Mellitus. Ethno Med. 2010; 4(3): 203-205. Available from: http: //www.krepublishers. com/02Journals/S-EM/EM.pdf

[47] Miller CK, Edwards L, Kissling G, et al. Nutrition Education Improves Metabolic Outcomes among Older Adults with Diabetes Mellitus: Results from a randomized controlled trial. Preventive Medicine. 2002; 34: 252-259. Available from: http://www.kr epublishers.com/02Journals/S-EM/EM.pdf PMid:11817922 http://dx.doi.org/10.1006/pmed.2001.0985

[48] Samtia AM, Rasool MF, Ranjha NM, et al. A Multifactorial Intervention to Enhance Adherence to Medications and Disease-Related Knowledge in Type 2 Diabetic Patients in Southern Punjab, Pakistan. Tropical Journal of Pharmaceutical Research October. 2013; 12(5): 851-856. Available from: http://www.tjpr.org/vol12_no5/2 013_12_5_28.pdf
[49] Orozco LJ, Buchleitner AM, Gimenez-Perez G, et al. Exercise or exercise and diet for preventing type 2 diabetes mellitus. Cochrane Database Syst Rev. 2008; (3): CD003054. Available from: http:// www.tjpr.org/vol12_no5/2013_12_5_28.pdf http://dx.d oi.org/10.1002/14651858.cd003054.pub3

[50] Hordern MD, Dunstan DW, Prins JB, et al. Exercise Prescription for Patients with Type 2 Diabetes and Pre-Diabetes: A position statement from Exercise and Sport Science Australia. Journal of Science and Medicine in Sport. 2012; 15: 25-31. Available from: http://exerciseismedicine.org.au/wp-conte nt/uploads/2012/04/ESSADiabetes.pdf PMid:21621458 ht tp: //dx.doi.org/10.1016/j.jsams.2011.04.005

[51] Li G, Zhang P, Wang J. The Long-Term Effect of Lifestyle Interventions to Prevent Diabetes in the China Da Qing Diabetes Prevention Study: a 20-year follow-up study. Lancet. 2008; 371: 1783-1789. Available from: http://exerciseismedicine.org.au/wp-c ontent/uploads/2012/04/ESSADiabetes.pdf http://dx.d oi.org/10.1016/S0140-6736(08)60766-7

[52] Ramachandran A, Snehalatha C, Mary S. The Indian Diabetes Prevention Programme Shows that Lifestyle Modification and Metformin Prevent Type 2 Diabetes in Asian Indian Subjects with Impaired Glucose Tolerance (IDPP-1). Diabetologia. 2006; 49: 289-297. Available from: http://exerciseismedicine.org.au/wp-conte nt/uploads/2012/04/ESSADiabetes.pdf PMid:16391903 ht $\mathrm{tp}$ ://dx.doi.org/10.1007/s00125-005-0097-z

[53] Lindstrom J, Ilanne-Parikka P, Peltonen M. Sustained Reduction in the Incidence of Type 2 Diabetes by Lifestyle Intervention: follow-up of the Finnish diabetes prevention study. Lancet. 2006; 368: 16731679. Available from: http://exerciseismedicine.org.au/ wp-content/uploads/2012/04/ESSADiabetes.pdf http:// $\mathrm{dx}$.doi.org/10.1016/S0140-6736(06)69701-8

[54] Kosaka K, Noda M, Kuzuya T. Prevention of Type 2 Diabetes by Lifestyle Intervention: a Japanese trial in igt males. Diabetes Res Clin Pract. 2005; 67: 152-162. Available from: http://exerciseismedicine.org.au/wp-content/u ploads/2012/04/ESSADiabetes .pdf PMid:15649575 http:// dx.doi.org/10.1016/j.diabres. 2004.06.010

[55] Nayak S, Maiya A, Hande M. Influence of Aerobic Treadmill Exercise on Blood Glucose Homeostasis In Non insulin Dependent Diabetes Mellitus Patients. Indian Journal of Clinical Biochemistry. 2005; 20(1). Available from: http://medind.nic.in/iaf/to 5/i1/iaft05i1p47.pdf PMid:23105493 http://dx.doi.org /10.1007/BF02893041 